The effect of $50 \%$ compared to $100 \%$ inspired oxygen fraction on brain oxygenation and post cardiac arrest mitochondrial function in experimental cardiac arrest

\title{
Nelskylä, Annika
}

2017-07

Nelskylä , A, Nurmi , J , Jousi , M , Schramko , A, Mervaala , E , Ristagno , G \& Skrifvars , M 2017 , ' The effect of $50 \%$ compared to $100 \%$ inspired oxygen fraction on brain oxygenation and post cardiac arrest mitochondrial function in experimental cardiac arrest ' , Resuscitation, vol. 116 , pp. 1-7 . https://doi.org/10.1016/j.resuscitation.2017.04.022

http://hdl.handle.net/10138/297805

https://doi.org/10.1016/j.resuscitation.2017.04.022

publishedVersion

Downloaded from Helda, University of Helsinki institutional repository.

This is an electronic reprint of the original article.

This reprint may differ from the original in pagination and typographic detail.

Please cite the original version. 
Experimental paper

\title{
The effect of 50\% compared to 100\% inspired oxygen fraction on brain oxygenation and post cardiac arrest mitochondrial function in experimental cardiac arrest ${ }^{\text {th }}$
}

\author{
Annika Nelskylä ${ }^{\mathrm{a}}$, Jouni Nurmi ${ }^{\mathrm{b}}$, Milla Jousi $^{\mathrm{b}}$, Alexey Schramko $^{\mathrm{c}}$, Eero Mervaala ${ }^{\mathrm{d}}$, \\ Giuseppe Ristagno ${ }^{\mathrm{e}}$, Markus B. Skrifvars ${ }^{\mathrm{a}, \mathrm{f}, *}$ \\ a Division of Intensive Care, Department of Anaesthesiology, Intensive Care and Pain Medicine, University of Helsinki and Helsinki University Hospital, \\ Finland \\ ${ }^{\mathrm{b}}$ Emergency Medicine and Services, Helsinki University Hospital and Department of Emergency Medicine, University of Helsinki, Finland \\ ${ }^{\mathrm{c}}$ Division of Anaesthesia, Department of Anaesthesiology, Intensive Care and Pain Medicine, University of Helsinki and Helsinki University Hospital, Finland \\ ${ }^{\mathrm{d}}$ Department of Clinical Pharmacology, University of Helsinki and Helsinki University Hospital, Helsinki, Finland \\ e Department of Cardiovascular Research, IRCCS - Istituto di Ricerche Farmacologiche "Mario Negri", Milan, Italy \\ ${ }^{\mathrm{f}}$ Australian and New Zealand Intensive Care Research Centre, School of Public Health and Preventive Medicine, Monash University, Melbourne, Victoria, \\ Australia
}

\section{A R T I C L E I N F O}

\section{Article history:}

Received 6 February 2017

Received in revised form 27 March 2017

Accepted 18 April 2017

\section{Keywords:}

Cardiac arrest

Cardiopulmonary resuscitation

Oxygen

\begin{abstract}
A B S T R A C T
Background and aim: We hypothesised that the use of 50\% compared to $100 \%$ oxygen maintains cerebral oxygenation and ameliorates the disturbance of cardiac mitochondrial respiration during cardiopulmonary resuscitation (CPR).

Methods: Ventricular fibrillation (VF) was induced electrically in anaesthetised healthy adult pigs and left untreated for seven minutes followed by randomisation to manual ventilation with $50 \%$ or $100 \%$ oxygen and mechanical chest compressions $\left(\right.$ LUCAS $^{\circledR}$ ). Defibrillation was performed at thirteen minutes and repeated if necessary every two minutes with $1 \mathrm{mg}$ intravenous adrenaline. Cerebral oxygenation was measured with near-infrared spectroscopy $\left(\mathrm{rSO}_{2}\right.$, INVOS ${ }^{\mathrm{TM}} 5100 \mathrm{C}$ Cerebral Oximeter) and with a probe (NEUROVENT-PTO, RAUMEDIC) in the frontal brain cortex $\left(\mathrm{PbO}_{2}\right)$. Heart biopsies were obtained 20 min after the return of spontaneous circulation (ROSC) with an analysis of mitochondrial respiration (OROBOROS Instruments Corp., Innsbruck, Austria), and compared to four control animals without $\mathrm{VF}$ and CPR. Brain $\mathrm{rSO}_{2}$ and $\mathrm{PbO}_{2}$ were log transformed and analysed with a mixed linear model and mitochondrial respiration with an analysis of variance.

Results: Of the twenty pigs, one had a breach of protocol and was excluded, leaving nine pigs in the $50 \%$ group and ten in the $100 \%$ group. Return of spontaneous circulation (ROSC) was achieved in six pigs in the $50 \%$ group and eight in the $100 \%$ group. The $\mathrm{rSO}_{2}(\mathrm{p}=0.007)$ was lower with $\mathrm{FiO}_{2} 50 \%$, but the $\mathrm{PbO}_{2}$ was not $(\mathrm{p}=0.93)$. After ROSC there were significant interactions between time and $\mathrm{FiO}_{2}$ regarding both $\mathrm{rSO}_{2}(\mathrm{p}=0.001)$ and $\mathrm{PbO}_{2}(\mathrm{p}=0.004)$. Compared to the controls, mitochondrial respiration was decreased, with adenosine diphosphate (ADP) levels of 57 (17) $\mathrm{pmol} \mathrm{s}^{-1} \mathrm{mg}^{-1}$ compared to 92 (23) pmol s $\mathrm{mg}^{-1}$ $(p=0.008)$, but there was no difference between different oxygen fractions $(p=0.79)$.

Conclusions: The use of $50 \%$ oxygen during CPR results in lower cerebral oximetry values compared to $100 \%$ oxygen but there is no difference in brain tissue oxygen. Cardiac arrest disturbs cardiac mitochondrial respiration, but it is not alleviated with the use of $50 \%$ compared to $100 \%$ oxygen (Ethical and hospital approvals ESAVI/1077/04.10.07/2016 and HUS/215/2016, $\S 7$ 30.3.2016, Funding Helsinki University and others).
\end{abstract}

(c) 2017 Elsevier B.V. All rights reserved.

\footnotetext{
is A Spanish translated version of the abstract of this article appears as Appendix in the final online version at doi: 10.1016/j.resuscitation.2017.04.022.

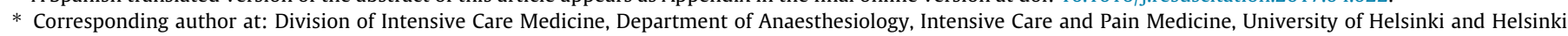
University Hospital, Haartmaninkatu 9, PL 266, 00029 HUS, Finland.

E-mail addresses: markus.skrifvars@monash.edu, markus.skrifvars@hus.fi, markus.skrifvars@helsinki.fi (M.B. Skrifvars).
} 


\section{Introduction}

According to current resuscitation guidelines, patients should be ventilated with the maximal feasible inspired oxygen concentration during cardiopulmonary resuscitation (CPR) [1]. After return of spontaneous circulation (ROSC), when oxygenation can be reliably monitored with peripheral pulse oximetry $\left(\mathrm{SpO}_{2}\right)$ or arterial blood gas $(A B G)$ analysis, the inspired oxygen should be titrated to the lowest possible level to achieve an arterial oxygen saturation of 94-98\%, with the intention to avoid hypoxia as well as hyperoxia, both of which are potentially harmful in the post-ischemic state following cardiac arrest (CA) [2]. Animal studies suggest that high arterial blood oxygen concentrations during reperfusion increase oxidative stress, worsening post-ischemic neuronal damage and adversely affecting the activity of the myocardial mitochondria [3-7]. Ventilation with lower fractions of oxygen during CPR might decrease the incidence of immediate hyperoxia after ROSC, but it is unclear if the use of lower oxygen fractions is enough to maintain adequate brain tissue oxygenation during CPR [5].

Means to non-invasively measure cerebral oxygenation during CPR include cerebral oximetry using near-infrared spectroscopy (NIRS), which estimates regional cerebral oxygen saturation $\left(\mathrm{rSO}_{2}\right)$ [8]. This enables continuous monitoring of brain oxygen saturation, and may capture oxygen delivery even without a pulsating rhythm, rendering it feasible during CPR [9]. However, its role in guiding CPR interventions has yet to be established. Invasive measurement of brain tissue oxygen is used in Neurocritical care, but it is not applicable in clinical CPR, unless the probe is in place prior to cardiac arrest [10].

In this randomised experimental animal study, we compared the effect of $100 \%$ and $50 \%$ oxygen fractions on cerebral oxygenation during and after CPR and their effects on the mitochondrial function of the myocardium. We hypothesised that the use of $50 \%$ oxygen during CPR would be enough to maintain brain oxygenation during $\mathrm{CPR}$, and this would decrease the incidence of extreme hyperoxia after ROSC. In addition we hypothesised that cardiac arrest disturbs cardiac mitochondrial function and the use of $50 \%$ oxygen would alleviate the disturbance of the respiratory function of the cardiac mitochondria [11].

\section{Material and methods}

This is an experimental animal study performed in healthy adult pigs. The study plan was approved by the Finnish National Animal Experiment Board (ESAVI/1077/04.10.07/2016) and by the hospital board (HUS/215/2016, $\S 7$ 30.3.2016). The study was conducted in the Research and Development Unit of Helsinki University Hospital, Helsinki, Finland, between March and June 2016. The study adhered to the ARRIVE guidelines, and a checklist is included in the Electronic Supplementary Material (ESM) [12].

\section{Preparation and monitoring}

We included twenty healthy landrace pigs of both genders, weighing $26-38 \mathrm{~kg}$, for the interventional part and four control pigs for the assessment of the effect of cardiac arrest on cardiac mitochondrial function. The control pigs were kept under general anaesthesia but did not have CA or CPR. Prior to the procedural day, the animals had free access to food and water. Thirty minutes before the procedure, the animals were pre-medicated with a mixture of ketamine (600 mg), atropine ( $1 \mathrm{mg}$ ) and medetomide $(2 \mathrm{mg})$ injected intramuscularly. A peripheral vein of the ear was cannulated, and an infusion of Ringer's acetate (Ringer-Acetat Baxter, Baxter Medical, Kista, Sweden) was started. The pigs were anesthetised with intravenous (IV) propofol (dose 20-100 mg) and fentanyl IV (100-200mcg) but without the use of paralytics. Anaesthesia was maintained with a continuous propofol infusion $(20 \mathrm{mg} / \mathrm{ml}, 5-25 \mathrm{ml} / \mathrm{h}$ ). The pigs were intubated (endotracheal tube size 6.0) and mechanically ventilated (Servo Ventilator 900C; Siemens-Elema, Solna, Sweden) with $21 \%$ oxygen $\left(\mathrm{O}_{2}\right)$ during the pre-arrest period. The ventilation targeted an end tidal carbon dioxide (etCO2) level of $5 \%$.

The internal jugular vein was cannulated using Seldinger's technique, and an introducer catheter (Arrow, size 7, French) was inserted for medications, venous blood sampling and pacemaker catheter insertion. A temporary balloon-tipped pacing wire was inserted, and correct placement in the right ventricular wall was confirmed by initiating pacing (Medtronic 5348 Single Chamber Temporary Pacemaker) and confrming the presence of multiple ventricular beats on the electrocardiogram (ECG). The femoral artery was prepared surgically and cannulated with a vascular sheath (Arrow, size 7, length $15 \mathrm{~cm}$ ) for invasive blood pressure measurement and for obtaining arterial blood samples. Oxygenation was monitored with pulse oximetry $\left(\mathrm{SpO}_{2}\right)$ attached to the pigs' tails. ABGs were measured with a point-of-care device (i-STAT System, Abbott Laboratories, Princeton, NJ).

Ventilation parameters such as tidal volume, respiratory pressure and inspired fractions of oxygen were monitored using a spirometry flow (D-Lite, GE Healthcare, USA) sensor connected to an airway module (GE DATEX OHMEDA). Haemodynamic and respiratory variables were measured and analysed using an AS/3 Monitor (Datex-Ohmeda AS/3, GE Healthcare, Helsinki, Finland) and stored on a computer using data collection software (iCentral ${ }^{\mathbb{R}}$ and S/5 Collect $^{\circledR}$, GE Healthcare, Helsinki, Finland). An oesophageal temperature probe was inserted, and a temperature of $38-39{ }^{\circ} \mathrm{C}$ was targeted to correspond the normal temperature of the pig, using an external radiant heater and a warming mattress [13].

\section{Cerebral oximetry and brain tissue oxygen}

Cerebral oximetry was monitored with near-infrared spectroscopy (INVOS ${ }^{\mathrm{TM}} 5100 \mathrm{C}$ Cerebral Oximeter, Somanetics Inc., Troy, MI, USA), fixed on the left side of the pigs' foreheads. For invasive brain tissue oxygen measurement, a cranial burr hole was performed on the right side of the forehead. A line was drawn from the orbit to the crossing of the parietal and midline sutures, and the location of the burr hole was at the second third from the orbit. A bolt kit was placed securely in the burr hole, and the dura was perforated. A probe (NEUROVENT-PTO, RAUMEDIC, Helmbrechts, Germany) was inserted and secured approximately $1 \mathrm{~cm}$ below the dura into brain tissue. The probe enables measurement of parenchyma intracerebral pressure and oxygen partial pressure. A data logger (MPR2 logO Datalogger, RAUMEDIC, Helmbrechts, Germany) was used for storing data.

\section{Experimental procedures}

Prior to the induction of ventricular fibrillation (VF), a baseline blood gas analysis was performed and sedation was ceased. VF was induced with a $4 \mathrm{~V}$ electrical current. The pigs were not ventilated during CA. After induction of CA, the pigs were randomised with sealed envelopes into two groups: ventilation during CPR with either $100 \%$ oxygen or $50 \%$ oxygen. At 7 min mechanical chest compressions (LUCAS ${ }^{\mathrm{TM}}$ Chest Compression System, Lund, Sweden) were initiated. Manual bag valve ventilation (LAERDAL Silicone Resuscitator, Norway) was started, with a frequency of $10 / \mathrm{min}$ with supplemental oxygen flow. The oxygen flow was titrated to achieve an inspired fraction of oxygen $\left(\mathrm{FiO}_{2}\right)$ of approximately $50 \%$ or $100 \%(2-15 \mathrm{l} / \mathrm{min})$ using continuous information obtained with the flow sensor (D-lite, Gas sampler and flow sensor, Ge Healthcare) between the endotracheal tube and ventilation bag and the 


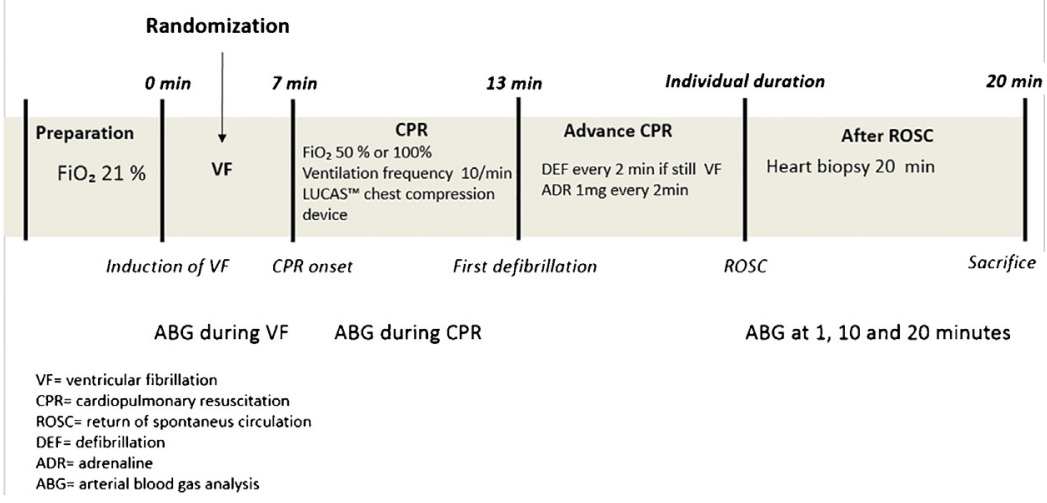

Fig. 1. Timeline of the experimental protocol.

airway module (GE DATEX OHMEDA). After 6 min of CPR, defibrillation was performed. If sinus rhythm was not achieved, a $1 \mathrm{mg}$ bolus of adrenaline (epinephrine) was administered IV and CPR was continued. Resuscitation continued with defibrillation (if still in a shockable rhythm) and boluses of adrenaline every $2 \mathrm{~min}$. CPR was continued until ROSC or for at least $20 \mathrm{~min}$, i.e. $27 \mathrm{~min}$ from CA. ROSC was defined as a sustained restoration of an organised cardiac rhythm with a mean arterial pressure (MAP) of more than $50 \mathrm{mmHg}$. If the animal had a clear transient pulsating rhythm but recurring VF, stacked immediate defibrillations were performed. Arterial blood gases were measured at predefined time points during $\mathrm{VF}$ and CPR (Fig. 1). After ROSC the $\mathrm{FiO}_{2}$ was maintained at $50 \%$ or $100 \%$ according to experimental group. The mean arterial pressure target was above $70 \mathrm{mmHg}$ with an infusion of noradrenaline $(0.04 \mathrm{mg} / \mathrm{ml})$. Twenty minutes after ROSC a lateral thoracotomy was performed to obtain a biopsy from the myocardium of the left ventricle. Before the incision the pigs received an additional dose of fentanyl, and their skin was infiltrated with a local anaesthetic (Lidocain 4\%, 20-30 ml). After the thoracotomy the pigs were sacrificed with a lethal $40-\mathrm{mmol}$ dose of potassium chloride. ABGs were measured at 1, 10 and 20 min after ROSC (Fig. 1).

\section{Mitochondrial respiration}

We assessed mitochondrial respiration using a previously described protocol, shown to capture changes occurring in the mitochondria of patients with cardiac failure [11]. After obtaining cardiac biopsies, the samples were immediately transferred into ice-cold relaxing and biopsy preserving solution (BIOPS20) for transport [14]. The samples weighed between $4.5-7.5 \mathrm{mg}$ and were homogenised, and mitochondrial respiration (i.e. adenosine triphosphate (ATP) production) was analysed using Oxygraph2k (OROBOROS Instruments Corp., Innsbruck, Austria) according to the manufacturer's specific instructions [14]. The oxygen flux was measured using a previously described fatty acid substrate uncoupler-inhibitor titration protocol, with a slight modification in the injection order $[11,15]$. The mitochondrial analysis is presented in detail in the ESM.

\section{Statistical analysis and sample size}

Continuous variables are reported as medians with interquartile, 25th and 75th range points (IQR) and categorical variables as counts and percentages. Categorical values were compared using Chi-square tests, and continuous values with Mann-Whitney $U$ tests. Due to differences in the baseline brain oxygen values, a baseline mean $\mathrm{PbO}_{2}$ value was calculated, and the values during CA, resuscitation and after ROSC were compared to this value. NIRS and proportional $\mathrm{PbO}_{2}$ were log transformed compared with a linear mixed effects model with compound symmetry as the covariance matrix, including MAP as a covariate. The analysis included the effect of interventional group, the effect of time and the interaction between time and intervention group. A significant time effect would suggest that $\mathrm{PbO}_{2}$ and $\mathrm{rSO}_{2}$ changes over time in the whole sample regardless of intervention. A significant intervention group effect would suggest that the groups are different, and a significant interaction between time and groups would suggest that the relationship between the interventions changes over time. Separate models were constructed for the VF period prior to CPR initiation, for CPR and $20 \mathrm{~min}$ after ROSC. Values over time were plotted with medians and IQR, and with mean and standard deviation shown in the ESM. As a sensitivity analysis, given likelihood of non-normal distribution of $\mathrm{PbO}_{2}$ and $\mathrm{rSO}_{2}$ data we also compared time all time points separately with a Mann-Whitney $U$ test. Values related to mitochondrial function were checked for normality using a Shapiro-Wilk test, and differences between the intervention groups and controls were measured with an analysis of variance test (ANOVA). In the case of a significant test result, a post hoc Fisher's least significant difference (LSD) test was performed. The sample size was estimated both regarding intra-arrest $\mathrm{PbO}_{2}$ and mitochondrial function. Using $\mathrm{PbO}_{2}$ values from a previous study (intra-arrest $\mathrm{PbO}_{2}$ with $100 \%$ oxygen of $5 \pm 3.5 \mathrm{mmHg}$ ) a study with nine animals in each group would be needed to show equivalence between interventions [16]. Regarding, the mitochondrial analysis using baseline data on mitochondrial respiration after succinate addition [15] and assuming a 40\% decrease overall in function with CA [11], four animals would be needed per group to show a $40 \%$ difference between the $50 \%$ and $100 \% \mathrm{FiO}_{2}$ groups. Given risk of technical failures we increased the total sample size to ten per group with five mitochondrial samples per groups. A $p$-value less than 0.05 was considered significant.

\section{Results}

Baseline period and ventricular fibrillation

A total of 20 animals were included in the study. In one case randomised to $50 \%$ oxygen, a breach of the experimental protocol occurred and the animal was defibrillated after just two minutes, followed by immediate ROSC. This case was excluded from the analysis, so the study sample therefore consisted of nine cases in the $50 \%$ group and ten cases in the $100 \%$ group. The groups were well balanced with regards to pre-arrest vital signs (Table 1) and blood gases (Table 2). During the baseline period the median $\mathrm{rSO}_{2}$ was 46 (43-50\%), and the median $\mathrm{PbO}_{2}$ was $33 \mathrm{mmHg}$ $\left(24-53 \mathrm{mmHg}\right.$ ). After CA induction both $\mathrm{rSO}_{2}(\mathrm{p}<0.001)$ and $\mathrm{PbO}_{2}$ $(\mathrm{p}<0.001)$ decreased over time, with no difference between groups (Figs. 2 and 3). There was no difference in blood gas values after 
Table 1

Vital signs and interventions during baseline, cardiac arrest, cardiopulmonary resuscitation and after return of spontaneous circulation in experimental cardiopulmonary resuscitation with ventilation with either $50 \%$ or $100 \%$ oxygen.

\begin{tabular}{|c|c|c|c|}
\hline & FiO2 $50 \%(n=9)$ & FiO2 $100 \%(n=10)$ & p-value \\
\hline \multicolumn{4}{|l|}{ Prearrest vital signs } \\
\hline $\mathrm{MAP}(\mathrm{mmHg})$ & $99(94-118)$ & $106(71-116)$ & 0.72 \\
\hline Heart rate & $135(104-143)$ & $122(112-134)$ & 0.78 \\
\hline $\mathrm{FiO}_{2}(\%)$ & $21(21-21)$ & $21(21-21)$ & 0.66 \\
\hline Ventilation rate & $20(16-25)$ & $20(16-21)$ & 0.50 \\
\hline $\mathrm{SaO}_{2}(\%)$ & $95(94-97)$ & $94(93-96)$ & 0.32 \\
\hline \multicolumn{4}{|c|}{ After 5 min of cardiac arrest } \\
\hline $\mathrm{MAP}(\mathrm{mmHg})$ & $23(18-26)$ & $25(18-27)$ & 0.50 \\
\hline Breath rate & $4(3-5)$ & $3(0-5)$ & 0.60 \\
\hline etCO $2(\%)$ & $1.6(1.3-1.9)$ & $1.0(0.7-1.4)$ & 0.13 \\
\hline \multicolumn{4}{|l|}{ Resuscitation } \\
\hline MAP (mmHg) & $37(21-53)$ & $42(34-48)$ & 0.78 \\
\hline etCO $_{2}(\%)$ & $4.4(3.4-4.6)$ & $4.3(2.4-5.0)$ & 0.66 \\
\hline $\mathrm{FiO2}(\%)$ & $46 \%(44-50)$ & $89 \%(88-89)$ & $<0.001$ \\
\hline Ventilation rate & $14(12-15)$ & $12(11-16)$ & 0.45 \\
\hline Tidal volume (ml) & $354(288-419)$ & $332(266-405)$ & 0.78 \\
\hline Defibrillations & $2(1-8)$ & $3(3-4)$ & 0.91 \\
\hline Adrenaline (mg) & $3(0-4)$ & $3(1-3)$ & 0.66 \\
\hline \multicolumn{4}{|l|}{ Outcome } \\
\hline ROSC & $6(67 \%)$ & $8(80 \%)$ & 0.51 \\
\hline Time to ROSC & $14(13-17)$ & $15.5(14-18)$ & 0.57 \\
\hline \multicolumn{4}{|l|}{ (minutes) } \\
\hline MAP 10 min after & $81(55-104)$ & $69(62-89)$ & 0.95 \\
\hline \multicolumn{4}{|l|}{$\mathrm{ROSC}(\mathrm{mmHg})$} \\
\hline etCO $2(\%) 10 \mathrm{~min}$ & $6.7(6.0-7.7)$ & $6.5(5.4-7.5)$ & 0.66 \\
\hline \multicolumn{4}{|l|}{ ROSC } \\
\hline $\mathrm{FiO}_{2}(\%)$ & $51(48-54)$ & $94(92-94)$ & 0.001 \\
\hline
\end{tabular}

Table 2

Blood gases during the intervention.

\begin{tabular}{|c|c|c|c|}
\hline & $\mathrm{FiO} 250 \%$ & FiO2 100\% & p-value \\
\hline \multicolumn{4}{|l|}{ Pre arrest } \\
\hline $\mathrm{PaO}_{2}(\mathrm{kPa})$ & $11.9(11.4-12.1)$ & $12.9(11.2-14.4)$ & 0.18 \\
\hline $\mathrm{PaCO}_{2}(\mathrm{kPa})$ & $4.9(4.5-5.4)$ & $4.8(4.2-5.2)$ & 1.0 \\
\hline $\mathrm{pH}$ & $7.54(7.50-7.6)$ & $7.57(7.47-7.63)$ & 0.55 \\
\hline $\mathrm{HCO}_{3}(\mathrm{mmol} / \mathrm{l})$ & $30.7(29.5-31)$ & $30.8(29.8-34.4)$ & 0.40 \\
\hline Lactate $(\mathrm{mmol} / \mathrm{l})$ & $1.2(1.0-1.7)$ & $1.2(0.7-1.5)$ & 0.50 \\
\hline \multicolumn{4}{|c|}{5 min of ventricular fibrillation } \\
\hline $\mathrm{PaO} 2(\mathrm{kPa})$ & $8.0(7.4-11.1)$ & $10.3(8.1-11.7)$ & 0.16 \\
\hline $\mathrm{PaCO} 2(\mathrm{kPa})$ & $2.9(2.5-4.0)$ & $2.8(2.3-4.6)$ & 0.72 \\
\hline $\mathrm{pH}$ & $7.71(7.61-7.76)$ & $7.71(7.59-7.80)$ & 0.50 \\
\hline $\mathrm{HCO} 3(\mathrm{mmol} / \mathrm{l})$ & $7(5-9)$ & $8(6-9)$ & 0.60 \\
\hline Lactate (mmol/l) & $28.4(26.2-29.9)$ & $28.6(27.7-29.8)$ & 0.66 \\
\hline \multicolumn{4}{|l|}{$5 \mathrm{~min}$ of $C P R$} \\
\hline $\mathrm{PaO} 2(\mathrm{kPa})$ & $8.5(8.1-10.4)$ & $15.6(9.8-21.0)$ & 0.025 \\
\hline $\mathrm{PaCO} 2(\mathrm{kPa})$ & $7.0(6.6-7.4)$ & $8.1(7.2-8.8)$ & 0.19 \\
\hline $\mathrm{pH}$ & $7.20(7.17-7.24)$ & $7.13(7.09-7.19)$ & 0.19 \\
\hline $\mathrm{HCO} 3(\mathrm{mmol} / \mathrm{l})$ & $20.819 .6-22.9)$ & $21.1(19.6-21.7)$ & 0.53 \\
\hline Lactate (mmol/l) & $10.2(9.1-10.4)$ & $10.7(9.0-11.6)$ & 0.55 \\
\hline \multicolumn{4}{|l|}{$1 \mathrm{~min}$ after ROSC } \\
\hline $\mathrm{PaO}_{2}(\mathrm{kPa})$ & $12.4(9.9-12.6)$ & $23.9(14.8-30.8)$ & 0.003 \\
\hline $\mathrm{PaCO}_{2}(\mathrm{kPa})$ & $8.6(8.6-8.9)$ & $8.5(7.9-10.1)$ & 0.39 \\
\hline $\mathrm{pH}$ & $7.00(6.92-7.09)$ & $7.00(6.95-7.05)$ & 1.0 \\
\hline $\mathrm{HCO}_{3}(\mathrm{mmol} / \mathrm{l})$ & $19(14.3-23.0)$ & $17.8(14.3-20)$ & 0.53 \\
\hline \multicolumn{4}{|l|}{10 min after ROSC } \\
\hline $\mathrm{PaO} 2(\mathrm{kPa})$ & $15.8(12.5-21.5)$ & $34.9(25.6-40.8)$ & 0.012 \\
\hline $\mathrm{PaCO} 2(\mathrm{kPa})$ & $8.0(6.7-9.7)$ & $8.6(7.5-9.9)$ & 0.53 \\
\hline $\mathrm{pH}$ & $7.02(6.85-7.19)$ & $7.08(6.96-7.12)$ & 0.86 \\
\hline $\mathrm{HCO} 3(\mathrm{mmol} / \mathrm{l})$ & $17.2(12.2-20.7)$ & $17.3(15.4-21.2)$ & 0.66 \\
\hline Lactate $(\mathrm{mmol} / \mathrm{l})$ & $10.6(9.3-13.2)$ & $12.4(10.7-14.2)$ & 0.49 \\
\hline \multicolumn{4}{|l|}{20 min after ROSC } \\
\hline $\mathrm{PaO}_{2}(\mathrm{kPa})$ & $14.5(10.8-16.8)$ & $36.5(23.0-53.3)$ & 0.029 \\
\hline $\mathrm{PaCO}_{2}(\mathrm{kPa})$ & $8.2(6.7-9.1)$ & $7.8(7.6-8.9)$ & 0.66 \\
\hline $\mathrm{pH}$ & $7.09(6.79-7.16)$ & $7.09(7.01-7.18)$ & 0.66 \\
\hline $\mathrm{HCO}_{3}(\mathrm{mmol} / \mathrm{l})$ & $17.6(11.9-21.3)$ & $18.3(16.9-23.3)$ & 0.41 \\
\hline
\end{tabular}

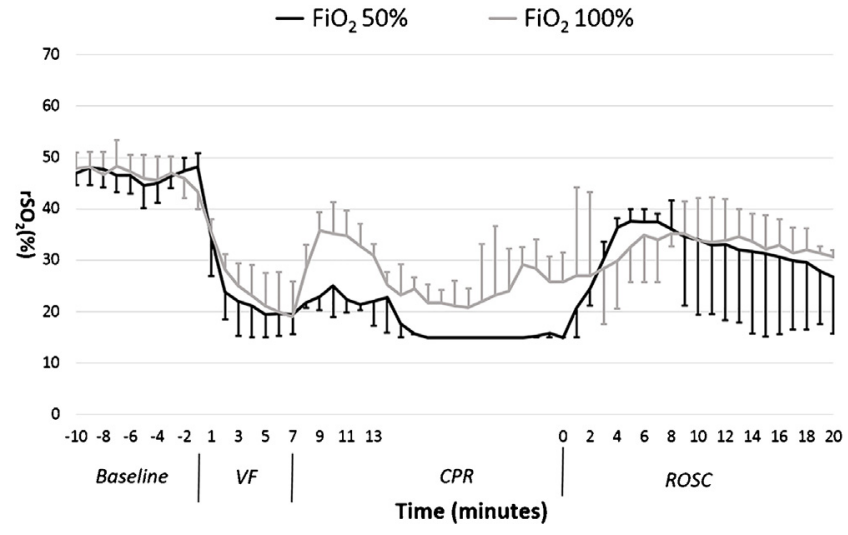

Fig. 2. The effect of ventilation with either $50 \%$ or $100 \%$ oxygen during experimental cardiopulmonary resuscitation on near infrared spectrometry and shown as median with 25 th or 75 th interquartile range point (only one shown in each group for clarity)

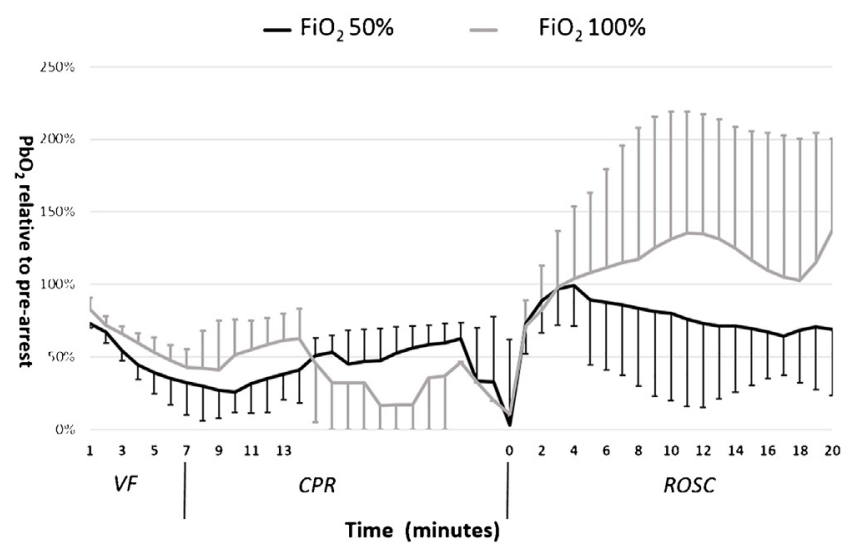

Fig. 3. The effect of ventilation with either $50 \%$ or $100 \%$ oxygen during experimental cardiopulmonary resuscitation on brain tissue oxygenation, measured with an intraparenchymal probe relative to baseline and shown as median with 25 th or 75 th interquartile range point (only one shown in each group for clarity).

5 min of VF (Table 2) between groups. During VF there was no difference in agonal breath rates, MAP or end tidal $\mathrm{CO}_{2}$ (Table 1 ).

\section{Cardiopulmonary resuscitation}

The measured $\mathrm{FiO}_{2}$ was different between groups during $\mathrm{CPR}$ and ROSC (Table 1 ). MAP, etCO ${ }_{2}$, tidal volumes and ventilation rates during $\mathrm{CPR}$ did not differ between animals randomised to $50 \%$ and $100 \% \mathrm{FiO}_{2}$ (Table 2). A median of three (IQR 1-4) defibrillation attempts and $3 \mathrm{mg}$ (IQR $1-4 \mathrm{mg}$ ) of adrenalin were needed to achieve ROSC, with no difference between groups. ROSC was achieved in six cases in the $\mathrm{FiO}_{2} 50 \%$ group and in eight cases in the $\mathrm{FiO}_{2} 100 \%$ group ( $\mathrm{p}=0.51$ ). The median time to ROSC from start of VF was 15 min (IQR 13-21), with no difference between groups (Table 1). The arterial $\mathrm{PaO}_{2}$ was significantly higher at 5 min of CPR and at all time points after ROSC in the $100 \%$ oxygen group compared to the $50 \%$ group (Table 2 ). There were no other differences in arterial blood gases during CPR or after ROSC. During CPR the prevalence of extreme hyperoxia $\left(\mathrm{PaO}_{2}>40 \mathrm{kPa}\right)$ was higher in the $\mathrm{FiO}_{2}$ $100 \%$ group compared to the $50 \%$ group ( 6 pigs vs. 0 pigs, $p=0.03$ ).

\section{Cerebral oximetry during CPR and after ROSC}

During $\mathrm{CPR} \mathrm{rSO}_{2}$ was significantly higher in the $100 \% \mathrm{FiO} 2$ group compared to the $50 \%$ group ( $\mathrm{p}=0.007$ ) but without significant interaction between FiO2 and time $(p=0.29)$. MAP during CPR was 


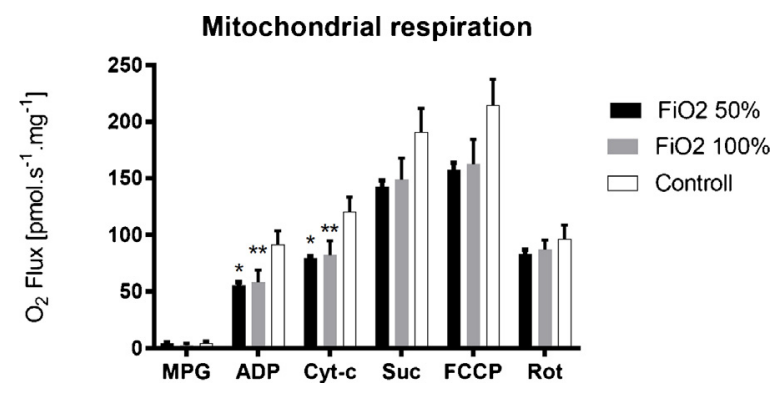

Fig. 4. Function of the cardiac mitochondria $20 \mathrm{~min}$ after the return of spontaneous circulation in animals ventilated with either $50 \%$ or $100 \%$ oxygen compared to control animals.

*p $<0.05$ for comparison between $\mathrm{FiO}_{2} 50 \%$ and controls.

** $\mathrm{p}<0.05$ for comparison between $\mathrm{FiO}_{2} 100 \%$ and controls.

not related to $\mathrm{rSO}_{2}(\mathrm{p}=0.76)$. After ROSC there was no difference between $\mathrm{FiO}_{2}$ groups $(\mathrm{p}=0.33$ ), but there was a significant interaction between $\mathrm{FiO}_{2}$ group and time $(\mathrm{p}=0.001)$. MAP was not related to pbO2 after $\operatorname{ROSC}(\mathrm{p}=0.35)$. With a non-parametric test $\mathrm{rSO}_{2}$ values were different between $\mathrm{FiO}_{2}$ groups $(\mathrm{p}<0.05)$ at $2-5$ min of CPR but not at other time-points. Median and mean rSO2 values over time are shown in Fig. 2 and in the ESM respectively.

\section{Brain tissue oxygen during CPR and after ROSC}

During CPR, there was no difference in the proportional brain tissue oxygenation changes between the two FiO2 groups (0.93), and no interaction between FiO2 and time (0.92). Mean arterial pressure recorded during CPR was related to brain tissue oxygenation $(\mathrm{p}<0.001)$. After ROSC, the proportional pbO2 increased in the $100 \%$ group towards the end of the 20 min period ( $p$-value for interaction between FiO2 group and time, $\mathrm{p}=0.004$ ). With a nonparametric test, there was significant difference in $\mathrm{PbO}_{2}$ at 19 and 20 min after ROSC $(\mathrm{p}<0.05)$ but not at other time-points. Median and mean $\mathrm{PbO} 2$ values over time are shown in Fig. 3 and in the ESM respectively.

\section{Analysis of mitochondrial function}

We obtained mitochondrial samples in five animals in each oxygen group and four controls. There were no differences in resuscitation factors between intervention groups among those 10 cases in which mitochondrial analysis was performed. Compared to the controls, mitochondrial respiration was decreased in the animals that had CA and were resuscitated, during the ADP and cytochrome C part of the titration protocol but not at later stages (Fig. 4). There were no significant differences in any of the mitochondrial measurements performed between the $100 \%$ and $50 \% \mathrm{FiO}_{2}$ groups (Fig. 4, ESM Supplementary Fig. 6). A complete set of measurements are shown in the ESM.

\section{Discussion}

The main findings of the present study are that even though the use of a $\mathrm{FiO}_{2}$ of $100 \%$ results in higher cerebral oximetry measured with NIRS compared to one of $50 \%$, there was no difference in oxygen measured in brain tissue. Brain tissue oxygenation during CPR seems to be dependent on the achieved perfusion pressure, which is the result of efficient chest compressions. After ROSC hyperoxia is common with $100 \%$ oxygen and its magnitude is slightly decreased with the use of $50 \%$ oxygen during CPR. CA results in a dysfunction of cardiac mitochondria, but this does not seem to be ameliorated with the use of a lower $50 \%$ compared to $100 \%$ oxygen fraction during or after CPR.
There are no randomised controlled trials on the use of oxygen during CA, and the evidence is mainly limited to observational studies and case reports. In a retrospective study, Spindelboeck and colleagues investigated the association between arterial oxygen during CPR and hospital admission rates after OHCA [17]. They analysed ABG samples obtained within $60 \mathrm{~min}$ of the initiation of chest compression in patients that were intubated and ventilated with $100 \%$ oxygen and receiving manual chest compressions. They found higher $\mathrm{PaO}_{2}$ values to be associated with an increased rate of hospital admission, but the patient sample size was underpowered for analysis of the neurologic outcome. The same investigators also conducted a prospective study in which an ABG was obtained during CPR [18]. As in their retrospective study, there was an association between increased $\mathrm{PaO}_{2}$ and higher rates of hospital survival.

In a unique case report from 2003, oxygen values during CPR were measured in an invasively monitored neurosurgical patient who had an iatrogenic cardiac arrest [10]. In this study by Imberti and colleagues, a strong association between cerebral perfusion pressure (CPP) and $\mathrm{PbO}_{2}$ was found. Our experimental results support the theory that the perfusion pressure achieved with effective chest compressions is of greater importance for brain tissue oxygenation than the used $\mathrm{FiO}_{2}$. Studies measuring $\mathrm{PbO} 2$ during neurocritical care have shown that increasing FiO2 and MAP increases PbO2 whereas hypocapnia decreases PbO2 [19].

The deleterious effects of hyperoxia have been studied mostly in animal studies, with a focus on the neurologic effects of hyperoxia and outcome [6,7]. Human data on the titration of $\mathrm{FiO}_{2}$ during and in post-resuscitation care are limited. In 2006 Kuisma and colleagues performed a randomised controlled trial comparing $30 \%$ to $100 \%$ oxygen in patients with ROSC after OHCA out-of-hospital CA [20]. The ROSC patients were either ventilated with $30 \%$ or $100 \%$ oxygen for $60 \mathrm{~min}$. Ventilation with $100 \%$ oxygen after resuscitation resulted in high arterial oxygen values and higher levels of the neurone-specific enolase, a marker of neurological injury [21]. In a prospective multicentre study, Young and colleagues compared titrated oxygen administration to standard care with high concentration oxygen use in a pre-hospital setting in OHCA patients [22]. The study was terminated when only 18 patients were recruited, as the preliminary data strongly suggested that delivering titrated oxygen therapy in a pre-hospital setting was not feasible. While the safe titration of oxygen delivery in OHCA seems difficult in such a setting, our study suggests that using a lower FiO2 level during CPR may decrease the incidence of extreme hyperoxia without compromising intra-arrest brain oxygenation.

NIRS is a non-invasive way to continuously monitor cerebral oxygen saturation and is easy to apply [8]. It provides information on the real-time status balance between oxygen delivery and uptake in regional cerebral tissue, but its feasibility and value in guiding therapy is unclear [8]. Some studies suggest that ROSC could be predicted from NIRS trends, but there is no threshold or exact NIRS value that ensures adequate oxygenation of the brain [23]. In our study the $\mathrm{FiO}_{2}$ used was associated with an $\mathrm{rSO}_{2}$ difference during CPR but not after ROSC, in line with a study by Putzer and colleagues [24]. After initiation of VF the $\mathrm{rSO}_{2}$ decreased, but during $\mathrm{CPR}$ the $\mathrm{rSO}_{2}$ was significantly higher in the group ventilated with $100 \%$ oxygen. During CPR the $\mathrm{rSO}_{2}$ seems to follow the oxygen content in the blood, but for titration of $\mathrm{FiO}_{2}$ it is probably not reliable since changes occur too slowly.

After successful resuscitation there are rapid changes in oxygen delivery. Hyperoxia may result in the increased production of reactive oxygen species (ROS). ROS are produced among others in mitochondria by the respiratory chain or by enzymatic reactions under physiologic conditions. Toxic effects of ROS include lipid peroxidation, protein oxidation and DNA damage [5,25]. Lipid peroxidation is one mechanism involved in the inhibition of the mitochondrial respiratory chain [26]. Only a few experimental 
studies have focused on mitochondrial function in heart muscle after CA. Angelos et al studied resuscitated rats and showed that mitochondrial function measured as respiration control ratio (RCR) was higher in animals ventilated with $40 \%$ compared to $100 \%$ oxygen [27]. Therefore, they suggested that hyperoxia may aggravate the injury of the respiratory chain function of the mitochondria in the heart [27]. In another rat model of CA and resuscitation, animals were ventilated during CPR and for $1 \mathrm{~h}$ after ROSC with $100 \%, 50 \%$ or $21 \%$ oxygen, followed by normoxic ventilation [28]. The used oxygen caused no differences between groups in terms of the restoration of ROSC or survival to $72 \mathrm{~h}$, but the use of $50 \% \mathrm{FiO}_{2}$ resulted in a reduced oxidative stress response as measured with 8-iso-prostaglandin F $\alpha 2$ as an indicator of ROS-mediated myocardial lipid peroxidation [28]. In our study with a large animal model, we detected a difference in mitochondrial function in resuscitated animals similar to that seen in patients with cardiac failure. We did not detect any difference between oxygen groups and thus refuted out hypothesis that $50 \%$ compared to $100 \%$ oxygen ameliorates disturbances in mitochondrial respiration. It is possible that our ventilation model did not cause severe enough hyperoxia or that the exposure was not long enough. Biomarkers of mitochondrial injury have recently been studied in human OHCA patients, indicating a differences between OHCA patients and controls, but without difference in survivors compared to non-survivors [29].

The results of the current study need to be interpreted taking into account both strengths and limitations. This experimental study was performed on pigs, which are considered to be a good large animal model for modelling CA [30]. The study was not blinded, but we aimed to standardise all procedures. The used animals were young and healthy and under general anaesthesia prior to the procedure. However, it is possible that the anaesthetic drugs might have influenced the results. The degree of hyperoxia in the current study was not as severe as in some previous clinical studies on hyperoxia after $\mathrm{CA}$, even though we used $100 \% \mathrm{FiO}_{2}$ [17]. Also the arterial carbon dioxide was high during CPR which might increase cerebral blood flow through cerebral vasodilatation and influence cerebral oxygenation. NIRS is feasible for monitoring of regional brain saturation in humans, but anatomical differences in the thickness of the forehead between pigs and humans might affect this value [31]. Regarding the mitochondrial analysis, we were only able to include 10 cases for analysis mainly due to logistical issues. We do feel that the samples are likely to be representative. In addition, we assessed mitochondrial at one point in time only, and it is possible that an earlier or later measurement would have resulted in different results. Finally, we did not include any marker of neurological injury and therefore cannot comment whether using 50\% oxygen during CPR ameliorates neurological injury.

\section{Conclusion}

In this experimental CPR model, manual ventilation with $50 \%$ compared to $100 \%$ oxygen resulted in lower cerebral oxygenation measured with NIRS but not in oxygen measured invasively in brain tissue. After ROSC brain oxygen increased rapidly, even with the use of a lower oxygen fraction during CPR. CA results in disturbed cardiac mitochondrial respiration, but this is not alleviated with the use of $50 \%$ oxygen.

\section{Conflict of interest}

Markus Skrifvars reports having received research grants from GE Healthcare, travel reimbursements and lecture fees from Orion Pharma, COVIDIEN, Astellas Pharma and Axis-Shield. All other authors report that they have no conflicts of interest.

\section{Acknowledgements}

This study was financed with unrestricted funding from Helsinki University (Three year research grant 2016-2018, H3702-11103568, wbs 73702705) and Helsinki University Hospital (State funding, VTR-Y102011094) and research grants from Stiftelsen Dorothea Olivia, Karl Walter och Jarl Walter Perkléns minne, Svenska Kulturfonden, Finska Läkaresällskapet and Medicinska Understödsföreningen Liv och Hälsa. The authors also wish to thank the staff of the Research and Development Unit of Helsinki University Hospital, i.e. Veikko Huusko and Olli Valtanen. In addition the authors would like to thank MD, PhD Johan Marjamaa for his help and advice regarding the $\mathrm{PbO} 2$ measurement.

\section{Appendix A. Supplementary data}

Supplementary data associated with this article can be found, in the online version, at http://dx.doi.org/10.1016/j.resuscitation. 2017.04.022.

\section{References}

[1]. Soar J, Nolan JP, Bottiger BW, Perkins GD, Lott C, Carli P, et al. European Resuscitation Council Guidelines for Resuscitation 2015: Section 3. Adult advanced life support. Resuscitation 2015;95:100-47.

[2]. Nolan JP, Soar J, Cariou A, Cronberg T, Moulaert VR, Deakin CD, et al. European Resuscitation Council and European Society of Intensive Care Medicine Guidelines for Post-resuscitation Care 2015: Section 5 of the European Resuscitation Council Guidelines for Resuscitation 2015. Resuscitation 2015;95:202-22.

[3]. Kilgannon JH, Jones AE, Shapiro NI, Angelos MG, Milcarek B, Hunter K, et al. Association between arterial hyperoxia following resuscitation from cardiac arrest and in-hospital mortality. JAMA 2010;303(21):2165-71.

[4]. Bellomo R, Bailey M, Eastwood GM, Nichol A, Pilcher D, Hart GK, et al. Arterial hyperoxia and in-hospital mortality after resuscitation from cardiac arrest. Crit Care 2011;15(2):R90.

[5]. Neumar RW. Optimal oxygenation during and after cardiopulmonary resuscitation. Curr Opin Crit Care 2011;17(3):236-40

[6]. Balan IS, Fiskum G, Hazelton J, Cotto-Cumba C, Rosenthal RE. Oximetry-guided reoxygenation improves neurological outcome after experimental cardiac arrest. Stroke 2006;12:3008-13.

[7]. Brucken A, Kaab AB, Kottmann K, Rossaint R, Nolte KW, Weis J, et al. Reducing the duration of $100 \%$ oxygen ventilation in the early reperfusion period after cardiopulmonary resuscitation decreases striatal brain damage. Resuscitation 2010;81(12):1698-703.

[8]. Cournoyer A, Iseppon M, Chauny JM, Denault A, Cossette S, Notebaert E. Nearinfrared Spectroscopy Monitoring During Cardiac Arrest: A Systematic Review and Meta-analysis. Acad Emerg Med 2016;8:851-62.

[9]. Meex I, De Deyne C, Dens J, Scheyltjens S, Lathouwers K, Boer W, et al. Feasibility of absolute cerebral tissue oxygen saturation during cardiopulmonary resuscitation. Crit Care 2013;17(2):R36.

[10]. Imberti R, Bellinzona G, Riccardi F, Pagani M, Langer M. Cerebral perfusion pressure and cerebral tissue oxygen tension in a patient during cardiopulmonary resuscitation. Intensive Care Med 2003;29(6):1016-9.

[11]. Lemieux H, Semsroth S, Antretter H, Hofer D, Gnaiger E. Mitochondrial respiratory control and early defects of oxidative phosphorylation in the failing human heart. Int J Biochem Biol 2011;43(12):1729-38.

[12]. Lemieux H, Semsroth S, Antretter H, Hofer D, Gnaiger E. Mitochondrial respiratory control and early defects of oxidative phosphorylation in the failing human heart. Int J Biochem Biol 2011;43(12):1729-38.

[13]. Muirhead MRAT. Managing pig health and the treatment of disease: a reference for the farm. 2nd edition PO Box 233: 5M Enterprises Ltd.; 1997.

[14]. Pesta D, Gnaiger E. High-resolution respirometry: OXPHOS protocols for human cells and permeabilized fibers from small biopsies of human muscle. Methods Mol Biol 2012;810:25-58.

[15]. Heinonen JA, Schramko AA, Skrifvars MB, Litonius E, Backman JT, Mervaala $\mathrm{E}$, et al. he effects of intravenous lipid emulsion on hemodynamic recovery and myocardial cell mitochondrial function after bupivacaine toxicity in anesthetized pigs. Hum Exp Toxicol 2017;36(April 4):365-75.

[16]. Yu J, Ramadeen A, Tsui AK, Hu X, Zou L, Wilson DF, uantitative assessment of brain microvascular and tissue oxygenation during cardiac arrest and resuscitation in pigs. Anaesthesia 2013;68(7):723-35.

[17]. Spindelboeck W, Schindler O, Moser A, Hausler F, Wallner S, Strasser C, et al. Increasing arterial oxygen partial pressure during cardiopulmonary resuscitation is associated with improved rates of hospital admission. Resuscitation 2013;84(6):770-5.

[18]. Spindelboeck W, Gemes G, Strasser C, Toescher K, Kores B, Metnitz P, et al. Arterial blood gases during and their dynamic changes after cardiopulmonary resuscitation: A prospective clinical study. Resuscitation 2016;106:24-9. 
[19]. Rosenthal G, Hemphill 3rd JC, Manley G. Brain tissue oxygen tension is more indicative of oxygen diffusion than oxygen delivery and metabolism in patients with traumatic brain injury. Crit Care Med 2009;37(1):379-80.

[20]. Kuisma M, Boyd J, Alaspaa A, Roine RO, Rosenberg P. Comparison of 30 and the $100 \%$ inspired oxygen concentrations during early post-resuscitation period: a randomised controlled pilot study. Resuscitation 2006;69(2):199-206.

[21]. Oksanen T, Tiainen M, Skrifvars MB, Varpula T, Kuitunen A, Castren M, et al. Predictive power of serum NSE and OHCA score regarding 6-month neurologic outcome after out-of-hospital ventricular fibrillation and therapeutic hypothermia. Resuscitation 2009;80(2):165-70.

[22]. Young P, Bailey M, Bellomo R, Bernard S, Dicker B, Freebairn R, et al. HyperOxic Therapy OR NormOxic Therapy after out-of-hospital cardiac arrest (HOT OR NOT): a randomised controlled feasibility trial. Resuscitation 2014;85(12):1686-91.

[23]. Parnia S, Yang J, Nguyen R, Ahn A, Zhu J, Inigo-Santiago L, et al. Cerebral Oximetry During Cardiac Arrest: A Multicenter Study of Neurologic Outcomes and Survival. Crit Care Med 2016;44(9):1663-74.

[24]. Putzer G, Braun P, Strapazzon G, Toferer M, Mulino M, Glodny B, et al. Monitoring of brain oxygenation during hypothermic CPR - A prospective porcine study. Resuscitation 2016;104:1-5.
[25]. Llitjos JF, Mira JP, Duranteau J, Cariou A. Hyperoxia toxicity after cardiac arrest: What is the evidence? Ann Intensive Care 2016;6(1):23.

[26]. Niki E. Lipid peroxidation: physiological levels and dual biological effects. Free Radic Biol Med 2009;47(5):469-84.

[27]. Angelos MG, Yeh ST, Aune SE. Post-cardiac arrest hyperoxia and mitochondrial function. Resuscitation 2011;82(Suppl 2):S48-51.

[28].Zhao S, Oian J, Wang J, Gong P, Yang Z, Cahoon J, et al. Effects of Oxygen Concentrations on Postresuscitation Myocardial Oxidative Stress and Myocardial Function in a Rat Model of Cardiopulmonary Resuscitation. Crit Care Med 2015;43(12):e560-6.

[29]. Donnino MW, Liu X, Andersen LW, Rittenberger JC, Abella BS, Gaieski DF, et al. Characterization of mitochondrial injury after cardiac arrest (COMICA). Resuscitation 2017.

[30]. Cherry BH, Nguyen AQ Hollrah RA, Olivencia-Yurvati AH, Mallet RT. Modeling cardiac arrest and resuscitation in the domestic pig. World J Crit Care Med 2015;4(1):1-12.

[31]. Murkin JM, Arango M. Near-infrared spectroscopy as an index of brain and tissue oxygenation. Br J Anaesth 2009;103(Suppl 1):i3-13. 